\title{
LARGE COUNTRIES, SMALL COUNTRIES AND THE ENLARGEMENT \\ OF TRADE BLOCS
}

\author{
Alessandra Casella
}

Working Paper 5365

\section{NATIONAL BUREAU OF ECONOMIC RESEARCH 1050 Massachusetts Avenue \\ Cambridge, MA 02138 \\ November 1995}

This paper is part of NBER's research program in International Trade and Investment. Any opinions expressed are those of the author and not those of the National Bureau of Economic Research.

( 1995 by Alessandra Casella. All rights reserved. Short sections of text, not to exceed two paragraphs, may be quoted without explicit permission provided that full credit, including $\odot$ notice, is given to the source. 


\title{
LARGE COUNTRIES, SMALL \\ COUNTRIES AND THE ENLARGEMENT \\ OF TRADE BLOCS
}

\begin{abstract}
Are there systematic forces such that countries of different sizes participating in a free trade bloc gain differently from the entry of new members? If economies of scale imply that firms located in large countries enjoy lower costs, then the gains from enlarging the bloc will fall disproportionately on small countries, because the entry of new members diminishes the importance of the domestic market and improves the small countries' relative competitiveness. The theoretical prediction is clear, but the empirical analysis of trade flows towards Spain and Portugal after their 1986 entry into the European Community yields mixed results. France and the U.K. appear to have lost market shares relative to the small countries in the Community, but the same is not true for Italy and, to a lesser degree, for Germany.
\end{abstract}

\author{
Alessandra Casella \\ Department of Economics \\ Columbia University \\ New York, NY 10027 \\ and NBER
}




\section{INTRODUCTION}

One effect of expanding the membership to the European Union has been to alter the relative power of the different countries in the deliberations of the Council of Ministers. The question remains at the center of much public attention: the relative power of each country depends not only on the number of votes it commands, but also on the distribution of votes among the other members, distribution that is bound to be disturbed by a change in the total number of countries. In a series of recent papers. Widgrén has calculated power indexes for the Council of Ministers under different scenarios involving increases in membership Midgrén. 1994a, 1994b). Although the conclusion can be qualified when different coalitional patterns are assigned different likelihoods, in general the power of the larger countries is reduced by the entry of new members: the admission of new countries increases the number of possible coalitions of smaller economies that can impose their preferences in matters subject to qualified majority.

The purpose of this paper is to analyze a preliminary question that should help us put this debate into perspective. There is no a priori reason why the countries' relative power should be left unchanged when the number of members is altered. From an economic point of view. a change in membership changes the distribution of gains from participation in the agreement. If political power within the agreement is linked to economic gains, if for example the countries that stand to gain the least from the enlargement have to be bribed to agree to it, wouldn't we expect a corresponding change in the distribution of political power? I ask in this paper whether there are systematic differences between large and small countries in the economic benefits they enjoy from the enlargement of a trade bloc. 
Notice that this question is different from asking whether a small or a large country will benefit more from establishing free trade between them, relative to autarky. In a neoclassical model of trade, in general the small country will experience the larger change in relative prices, and the larger welfare gain; in a monopolistically competitive model again the small country will typically be the main beneficiary, for example through the effect of enhanced consumption variety on welfare.

The question is also different from asking whether a small or a large country will benefit more from joining a free trade bloc. The same mechanisms described in the previous paragraph will typically work here, and in general the small country will again be the country to gain the most.

But what happens to countries of different sizes that are already part of a free trade agreement when new members join the bloc? Neoclassical theory does not give us an unambiguous answer. Because prices have already been equalized within the bloc, the impact of the new entrants on each old member depends on the relationship between their endowments. We cannot derive a general conclusion based on size alone.

Because the question focuses on the role of size, the paper starts from the assumption that scale factors are important. Consider a world where countries have domestic markets of different sizes, and where there are some barriers to entry to all foreign markets, although the barriers are small in the case of fellow members of a trade agreement. Firms located in larger countries benefit from the large domestic markets, and are able to exploit economies of scale and produce at lower costs than firms located in smaller countries. Now suppose that countries outside the trade bloc were to enter the agreement.'

It may appear at first that firms in large countries would have a privileged position. Because they have lower costs, they should be able to gain disproportionately large shares of the new trade, and realize larger extra profits than firms in small countries. Indeed the argument is 
often heard in public discussions.

Yet. this view is mistaken because it neglects the original cause of the difference in economic performance between large and small countries. By increasing the size of the market to which all firms have relatively easy access. the enlargement of the trade bloc decreases the importance of the domestic market and plays in favor of the small countries. Building on the Krugman-type model developed by Baidwin (1993), this paper shows that the gains from expanding the membership of the trade bloc fall disproportionately on the small countries.

In the last part of the paper. the theoretical conclusion is tested by looking at the impact of the 1986 entry of Spain and Portugal in the European Community. The data show that. after 1986, exports from France and the U.K. have indeed lost market shares in Spain and Portugal, relative to exports from the small Community countries (controlling for changes in economic size and real exchange rates). However, the theoretical prediction is rejected in the case of Italy and. although less sharply, in the case of Germany. Several factors may explain the mixed results, but reaching a clear conclusion will require a longer sample, or a comparative analysis of different episodes.

While we wait for the data to accumulate, the European Union expands, and further enlargements are planned for the future: similarly, the expansion of NAFTA is being considered. We hope that the simple argument exposed by this paper may be of some help in the discussion of these future developments.

The paper is organized as follows. The next section describes the model; Sections III and IV analyze its solution and results; Section $V$ discusses the empirical evidence from the 1986 enlargement, and Section VI concludes. Formal proofs are presented in the Appendix. 


\section{THE MODEL}

To study the importance of scale factors within a trade bloc, we need a model with two essential features: there must be economies of scale that will allow firms located in larger markets to have lower costs; and domestic firms must benefit from easier access to the domestic market even within the bloc. A simple model satisfying these requirements is discussed in Baldwin (1993) and is derived from the set-up developed by Krugman in his work on economic geography (see for example, Krugman, 1991a, 1991b). Baldwin's model does not distinguish between small and large countries. In what follows, I adapt his framework to our purposes.

The world is composed of $\mathrm{N}$ countries. A number of them belong to a trade bloc, while the remaining countries, in number $N_{0}$, do not. Participation in the trade bloc means that trade with other member countries encounters fewer obstacles than trade with countries outside the bloc. Obstacles to trade could have many sources, but are summarized in a measure of transport costs: between member countries, one unit of consumption of the foreign good requires a shipment of $\mu$ units. On the other hand, citizens of a country that is not member of the bloc must purchase $\tau$ units of each foreign good to achieve one unit of consumption, where $\tau$ is larger than $\mu$. Domestic trade is easier than any form of international trade: one unit of consumption is achieved with one unit purchased, while both $\tau$ and $\mu$ are larger than 1 .

In each country, there is a fixed number of immobile skilled workers $\mathrm{H}$. For simplicity, I assume that all countries outside the bloc have the same skilled population $\mathrm{H}_{0}$; within the bloc $N_{L}$ countries have skilled population $H_{L}$, and are called "large", $N_{s}$ have skilled population $H_{s}$, and are called "small" ( $H_{L}$ is larger than $\left.H_{S}\right)$.

In addition to skilled labor, there is a world supply of unskilled workers $L$. Although 
unskilled workers cannot migrate to and from countries outside the trade bloc, they can move among the countries belonging to the bloc. ${ }^{2}$ Thus the proportion of skilled to unskilled labor is fixed in countries outside the bloc, but within the bloc will be determined in equilibrium. In each country $\mathrm{J}$, such proportion is represented by the parameter $\theta_{\mathrm{J}}$ :

$$
H_{J}=\theta_{J} L
$$

All workers are endowed with one unit of labor, which they supply at the market wage for their type of labor in the country where they reside. They all have identical Dixit - Stiglitz preferences:

$$
U=\left[\sum_{i=1}^{K} c_{i}^{(0-3)) / 0}\right]^{o(\alpha-1)}
$$

where $c_{i}$ is consumption of variety $i$ of a differentiated good, $K$ is the total number of available varieties, and the parameter $\sigma$, larger than 1 , is the elasticity of substitution across varieties and, if the number of varieties is large, the elasticity of demand of each variety to its price.

Both types of labor are required in the production of all varieties. The technology, common to all countries, is given by:

$$
Y_{1}=\max \left(0,\left(H_{i} L_{i}\right)^{1 / 2}-Y_{F}\right)
$$

where $Y_{i}$ is the output of variety $i$ available for sale, $Y_{F}$ is a fixed cost, sustained in terms of output, and $H_{i}$ and $L$ are skilled and unskilled labor employed in the production of variety $i$. The presence of fixed costs insures that each firm will specialize in one variety.

In each country, the number of firms is given. Firms are owned by domestic skilled workers, and if profits are positive, these workers receive the profits as dividends. ${ }^{3}$. 
An equilibrium of this model specifies the prices of all varieties of goods, the distribution of low-skill workers among the countries in the trade bloc, the wages of the two types of labor in all countries, and the profits realized by each firm such that all markets clear, consumers maximize their utility, firms maximize profits, and no low-skill worker can benefit from migration within the trade bloc.

The building blocks of the model are well-known and provide a traditional description of monopolistic competition and trade among similar countries. There are four innovations. The first one, borrowed from Baldwin (1993), is the assumption of different transport costs and captures as simply as possible the essence of a trade bloc. The second innovation is the assumption of countries of different sizes, which is at the center of the question we want to ask. Together with transport costs, the difference in sizes will imply lower consumer prices in large countries. In the presence of labor mobility within the bloc - our third less traditional assumption - the difference in consumer prices will result in lower unskilled wages in large countries. In equilibria where factor proportions are similar across countries, lower unskilled wages will lead to lower producer prices for firms located in large countries. Large countries' firms will control a larger share of any foreign market, and make positive profits. Thus together these three assumptions capture the advantage of a larger domestic market. Finally, the assumption of different mobility for the two types of labor will yield different national welfare in the different countries, even as unskilled migration anchors the wage."

In this model, where the only factor of production is labor, economies of scale are tied to differences in wages. But this is not meant to be interpreted literally. The important point is more generally that a larger domestic market allows firms to lower their production costs: there is a direct link between the size of the domestic market and competitiveness. 


\section{SOLUTION}

\section{Consumers}

Consider consumer $j$, with nominal income $E_{i}$. Given the presence of transport costs and utility function (2), it is well-known that j's demands for the different varieties will satisfy:

$$
\begin{array}{ll}
x_{i, j}=c_{i, j}=\left(p / P_{i}\right)^{\circ} E_{i} & \text { if variety } i \text { is produced domestically; } \\
x_{i, j}=\mu c_{i, j}=\mu^{\prime \sigma}\left(p / P_{i}\right)^{\circ} E_{i} & \begin{array}{l}
\text { if variety } i \text { is produced in a country with which } j \text { 's country has a } \\
\text { trade agreement; }
\end{array} \\
x_{i, j}=\tau c_{i, j}=\tau^{10}\left(p / P_{i}\right)^{\circ} E_{i} & \begin{array}{l}
\text { if variety } i \text { is produced in a country with which } j \text { 's country has no } \\
\text { trade agreement; }
\end{array}
\end{array}
$$

where $x_{i, j}$ is demand of variety $i$ by $j, c_{i, j}$ is consumption, $p_{i}$ is the price of variety $i$ and $P_{i}$ is the price deflator faced by $j$. The price deflator, corresponding to the minimum expenditure that $j$ must incur to achieve one unit of utility, is given by:

$$
P_{i}=\left[\sum_{i=1}^{k} p_{i}^{10}+\sum_{i=1}^{k^{*}}\left(\mu p_{i}\right)^{10}+\sum_{i=1}^{x^{* *}}\left(\tau p_{i}\right)^{10}\right]^{-110}
$$

where $k$ is the number of varieties produced domestically, $k^{\star}$ the total number of varieties produced in countries with which j's country has a trade agreement, and $k^{\star \star}$ the total number of varieties produced in countries with which j's country has no agreement.

Indirect utility of consumer j equals:

$$
U_{1}=E_{i} P_{i}^{-\infty /(a-1)}
$$

\section{Firms}


Consider firm i located in country $j$. With the technology described by equation (3), its costs are given by:

$$
C_{i i}\left(W^{h}, W_{j}^{n}, Y_{F}, Y_{i}\right)=2\left(W^{h}, W_{j}^{n}\right)^{1 / 2}\left(Y_{F}+Y_{i j}\right)
$$

where $w^{h}$, and $w^{n}$, are the wages paid to skilled and unskilled employees. The Cobb-Douglass technology insures that the two types of labor will be employed in each firm according to:

$$
H_{i} / L_{4}=w^{n} / w_{1}^{n}
$$

In a symmetrical equilibrium where all firms within a given country are identical, the relative wage of skilled and unskilled labor reflects the proportions of the two types of labor in the population:

$$
w_{1}^{n}=\theta_{1} w_{1}^{n}
$$

In what follows, (9) will be used to eliminate the unskilled wage from all equations, and the symbol $w$, with no superscript, will refer to the skilled wage.

Each firm will set the price of the variety it produces so as to equate marginal revenues and marginal costs. With demands given by (4) and costs given by (7), this condition implies that the price of variety i produced in country j will equal:

$$
p_{i}=(\sigma /(\sigma-1)) 2 w_{1} \theta_{1}^{12}
$$

Given (7) and (10), we can derive the scale of production of each firm as function of the profit rate. If firm i's revenues amount to $\left(1+\pi_{i}\right)$ times its total costs:

$$
p_{i} Y_{i}=\left(1+\pi_{i}\right) 2 w_{i} \theta_{l}^{1 / 2}\left(Y_{F}+Y_{i j}\right)
$$

then, substituting $p_{1}$ from (10), we find: 


$$
Y_{i j}=\frac{\left(1+\pi_{i}\right)(\sigma-1)}{1-\pi_{i j}(\sigma-1)} Y_{F}
$$

With no rigidities in the labor market, labor will be fully employed. Because each firm specializes in the production of one variety, if all firms in the country are symmetrical, then:

$$
\left(H_{1} L_{i}\right)^{1 / 2}=k_{i}\left(Y_{i}+Y_{F}\right)=k_{i} \frac{\sigma Y_{F}}{1-\pi_{i}(\sigma-1)}
$$

where $k_{i}$ is the number of varieties produced in country $j$ - which equals the number of firms in country j. Equation (13) can be solved for $\pi_{i}$ :

$$
\pi_{1}=\max \left(0, \frac{H_{j}-k_{i} \theta_{j}^{1 / 2} \sigma Y_{F}}{H_{i}(\sigma-1)}\right)
$$

Given (14) and (12), it is easy to calculate total profits in $j$. In addition, because profits are distributed as dividends to domestic skilled workers, each skilled worker in j receives dividends $d_{i}$ given by:

$$
d_{i}=k_{i} \frac{\pi_{i} 2 w_{i} \theta^{1 / 2}\left(Y_{F}+Y_{i}\right)}{H_{i}}=2 \pi_{i} w_{i}
$$

The firms' problem is now completely solved. Equation (10) gives the optimal price, equation (12) the scale of production, and equation (14) the profit rate as function of the parameters of the model, and, in each country, the number of firms, the proportion of skilled to unskilled labor, and the level of skilled wages.

\section{Equilibrium}


Within the trade bloc, unskilled workers are mobile. In equilibrium, their utility in large and small countries belonging to the bloc must be equalized. The only source of income of unskilled workers is their wage, which we know proportional to the skilled wage. Thus indirect utility (6) implies:

$$
\theta_{L} W_{L} P_{L}^{-a(10-1)}=\theta_{S} W_{S} P_{S}^{-\sigma(10)}
$$

where the subscripts $L$ and $S$ indicate the realization of the variable in a large and in a small country in the bloc.

Substituting the price equation (10) in (5) and using the skilled wage in countries outside the bloc as the numeraire, we obtain the price deflators in the three types of countries:

$$
\begin{aligned}
& P_{S}=a^{(0 \cdot 1) / \sigma}\left[\left(\theta_{s}^{1 / 2} W_{S}\right)^{10} k_{s}\left(1+\left(N_{S}-1\right) \mu^{10}\right)+N_{L} k_{L}\right. \\
& \left.+N_{0} k_{0}\left(\theta_{0}^{1 / 2} \tau\right)^{10}\right]^{1 / 0} \\
& P_{L}=a^{(0-1) / \sigma}\left[\left(\theta_{L}^{1 / 2} W_{L}\right)^{10} k_{L}\left(1+\left(N_{L}-1\right) \mu^{1-\sigma}\right)+N_{s} k_{S}\right. \\
& \left.+N_{0} k_{0}\left(\theta_{0}^{1 / 2} \tau\right)^{10}\right]^{-1 / 0} \\
& P_{0}=a^{(0.1) / 0}\left[k_{0} \theta_{0}{ }^{(1-0) / 2}\left(1+\left(N_{0}-1\right) \tau^{10}\right)+N_{L} k_{L}\left(\tau \theta_{L}{ }^{1 / 2} W_{L}\right)^{1}\right. \\
& \left.+N_{s} k_{s}\left(\tau \theta_{s}{ }^{1 / 2} W_{s}\right)^{10}\right]^{-1 / 0} \\
& a \equiv\left(\frac{2 \sigma}{\sigma-1}\right)
\end{aligned}
$$

where the subscript $o$ indicates the realization of a variable in a country outside the trade bloc. In countries outside the bloc there is no migration of unskilled labor, and the proportion of skilled to unskilled workers is given:

$$
\theta_{0}=\theta
$$

Total unskilled labor must add up to a fixed world supply: 
$N_{L} L_{L}+N_{S} L_{S}+N_{0} L_{0}=L$

Given (18) and a fixed supply of skilled workers in each country, this constrains feasible factor proportions in the countries belonging to the bloc:

$$
\frac{N_{L} H_{L}}{\theta_{L}}=L-\frac{N_{0} H_{0}}{\theta_{0}} \cdot \frac{N_{S} H_{S}}{\theta_{S}}
$$

Equations (16) and (20) characterize the equilibrium in the factors market.

In goods market, the quantity supplied of each variety must equal the total quantity demanded. Equation (12) describes the quantity available for sale. Equations (4) describe individual demands by domestic and foreign consumers, as function of relative prices and of consumers' nominal incomes. Prices are given by equations (10) and (17); nominal incomes of unskilled workers equal unskilled wages; nominal incomes of skilled workers include both skilled wages and dividends, given by equation (15). Adding up individual demands, we obtain the equilibrium conditions:

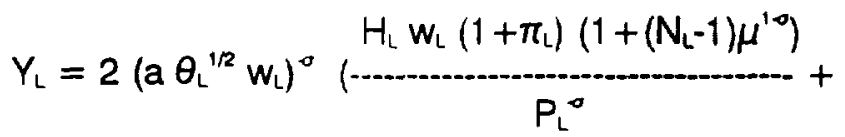

$$
\begin{aligned}
& +\frac{H_{s} W_{s}\left(1+\pi_{s}\right) N_{s} \mu^{1 \sigma}}{P_{s}^{0}} \frac{H_{0}\left(1+\pi_{0}\right) N_{0} \tau^{10}}{P_{0}^{0}} \\
& Y_{s}=2\left(a \theta_{s}^{1 / 2} W_{s}\right)^{\circ} \frac{H_{s} W_{s}\left(1+\pi_{s}\right)\left(1+\left(N_{s}-1\right) \mu^{1 \sigma}\right)}{P_{s}^{0}}+ \\
& \left.+\frac{H_{L} W_{L}\left(1+\pi_{L}\right) N_{L} \mu^{i \sigma}}{P_{L}^{0}}+\frac{H_{0}\left(1+\pi_{0}\right) N_{0} \tau^{10}}{P_{0}^{0}}\right)
\end{aligned}
$$


where $Y_{L}$ and $Y_{S}$ are given by (12).

Walras' law guarantees that if goods markets are in equilibrium in large and small countries in the trade bloc, then they are also in equilibrium in countries outside the bloc.

The model is now completely solved. Given the number of firms in each country and the relationship between the number of firms and the profit rate implied by full employment (equation 14), the four equilibrium conditions (16), (20), (21a) and (21b) determine the proportion of skilled to unskilled labor and the skilled wage in large and small countries belonging to the trade bloc $\left(\theta_{L}, \theta_{S}, W_{L}, W_{S}\right)$.

\section{RESULTS}

\section{Equilibrium}

As is often the case in this type of models, the equilibrium conditions do not yield simple closed-form solutions. We can investigate the characteristics of the equilibrium through numerical exercises, for different values of the parameters. Or we can follow an alternative strategy and prove analytically some properties of the solution, if we are willing to limit the range of equilibria under consideration. This second approach is followed here. As stated above, in general a different initial distribution of firms across the three types of countries results in different factor proportions in each economy; thus by constraining the exogenous number of firms we can select particular equilibria. Suppose that the number of firms is such that the equilibrium, if it exists, is characterized by equal ratios of skilled to unskilled workers in all countries. In what follows, I discuss the properties that such an equilibrium must satisfy. Although this equilibrium relies on specific values for the exogenous variables, it is an interesting reference point because it captures an empirical fact: in Europe there is no 
systematic relationship between country size and human capital abundance. In addition, it has the advantage of making most transparent the competitive advantage enjoyed by firms located in larger domestic markets. The effects of enlarging the trade bloc, discussed in the next section, will not depend on the specific choice of the initial equilibrium. ${ }^{5}$

The presence of transport costs in international transactions, coupled with the bigger domestic market of the large countries, lead us to expect that in equilibrium consumer prices will be lower in large countries. If factor proportions are equal in all countries, this implies lower wages for both types of workers and lower producer prices. The lower producer prices should then lead to higher demand for each variety produced in a large country, and higher profits. The following propositions - proved in the Appendix - make these intuitions more precise.

Proposition 1. Consider an equilibrium where $\theta_{\mathrm{L}}=\theta_{\mathrm{s}}=\theta_{0}$. Then, for any $w_{\mathrm{s}}{ }^{*}<w_{\mathrm{L}}$, there exists $a \mu^{\circ}>1$ such that for all $\mu<\mu^{\circ}, w_{s}{ }^{*}$ cannot occur in equilibrium.

The proposition states that, in a symmetrical equilibrium, low enough transport costs within the trade bloc are a sufficient condition for lower consumer prices, wages and producer prices in large countries. Higher wages in large countries would require higher consumer prices. This could occur only if the number of varieties produced domestically were sufficiently low, or, equivalently, if privileged access to a larger domestic market guaranteed sufficiently high demand for each variety at any price. Low enough transport costs rule out this possibility.

Proposition 2. Consider an equilibrium where $\theta_{\mathrm{L}}=\theta_{\mathrm{s}}=\theta_{\alpha}$. Then, for any $w_{\mathrm{s}}{ }^{*}>w_{\mathrm{L}}$, there exists $a \mu^{*}>1$ such that for all $\mu<\mu^{*}, \pi_{L}>\pi_{s}$.

Lower producer prices in large countries should lead to higher demand for each variety and to a higher profit rate. However, if markets were very segmented, demand in each country would fall almost exclusively on domestic varieties; in this scenario it would be plausible for demand in large countries to be sufficiently depressed by low profits to generate indeed low 
profits, regardless of prices and profits abroad. Low enough transport costs again rule out this possibility.

Notice that if the profit rate is higher in large countries, the distribution of firms that supports the symmetrical equilibrium must imply a lower density of firms per worker in large countries (equation 14): in a symmetrical equilibrium large countries have larger firms.

What is welfare of unskilled and skilled workers in the different countries in this equilibrium? A relative ranking of utilities is not difficult to establish. Call $U_{j}^{\prime}$ the realized utility of a worker of type $i(i=h, n)$ in country $j$. Then we can establish the following Proposition:

Proposition 3. Consider an equilibrium where $\theta_{\mathrm{L}}=\theta_{\mathrm{s}}=\theta_{\sigma}$. Then:

$$
\begin{array}{ll}
U_{1}^{n}>U_{1}^{n} & \forall j \text { if } \theta<1 \\
U_{1}^{n}=U & \forall j \text { belonging to the bloc } \\
U_{1}^{n}>U_{s}^{n} & \forall \mu<\mu^{*}, V L, \text { s belonging to the bloc. } \\
U_{1}^{n}>U_{z}^{n} & \forall j \text { belonging to the bloc, } z \text { not belonging to the bloc. } \\
U_{1}^{n}>U_{2}^{n} & \forall z \text { not belonging to the bloc, and j belonging to the bloc where: } \\
& j=\begin{array}{l}
L, S \text { if } z=S \\
L, \quad \text { if } z=L
\end{array}
\end{array}
$$

If skilled workers are scarcer than unskilled ones in all countries, then everywhere their wage is a multiple of the unskilled wage, and their utility must be higher. Mobility insures that unskilled workers in countries belonging to the bloc have equal utilities. But because skilled workers do not migrate, their utility in different countries can differ. Using (6), (15) and (16), we obtain:

$$
\frac{U_{L}^{*}}{U_{s}^{*}}=\frac{\theta_{s}}{\theta_{L}} \frac{1+2 \pi_{L}}{1+2 \pi_{S}} \quad \forall L, S \text { belonging to the bloc; }
$$


If the shares of skilled to unskilled population are equal everywhere, the first term equals $1:$ the utility derived from wage income is equalized. But because skilled workers also earn dividends, their utility must be higher in countries where firms realize higher profit rates. Propositions 1 and 2 insure that if transport costs within the bloc are not too high, skilled workers within the bloc must be better off in large countries.

Finally, comparing workers within and outside the trade bloc, notice that outside the bloc wages and profits are lower, while consumer prices are higher. Therefore utility is lower.

\section{Comparative Statics}

Suppose now that a number of countries previously outside the bloc were to enter the trade agreement. How would the equilibrium be modified, for given values of the exogenous variables?

Let us take as initial condition a symmetrical equilibrium with equal factor proportions across countries. The entry of the new members will have two effects: it will cause migration flows of unskilled workers, modifying factor proportions in different countries, and it will affect relative wages across countries, and thus relative costs and producer prices. The change in producer prices will be reflected immediately in changes in relative sales, and thus in profits, in large and small countries.

These repercussions are triggered by the possibility of migration. But migration would not take place, and relative wages would not move, if relative price deflators in small and large countries were unchanged. In the presence of transport costs, it is relative price deflators that capture the importance of domestic markets of different sizes, and in this model it is labor migration that links the difference in consumer prices to differences in firms' competitiveness. The same two mechanisms translate the entry of new members into the bloc into changes in 
wages and profits in small and large countries. Small countries are more dependent on foreign trade, and we expect a stronger impact of enlargement on their cost of living. Although the model is not simple enough to prove this conclusion in equilibrium, it is not difficult to see that this guess is correct at given wages and profits. ${ }^{7}$

We can conjecture the following adjustment: The larger decline in the cost of living in small countries attracts a proportionately larger share of unskilled migration. Total employment increases by a higher percentage in small countries; with a fixed number of firms, output per firm must increase by a higher percentage, implying a relative gain in competitiveness and profit rates.

A series of numerical exercises have confirmed these results. Figures 1 and 2 report factor proportions in both types of countries, relative prices per variety produced, relative sales per variety and relative profits per skilled worker in large versus small countries, as functions of the proportion of the world belonging to the trade bloc for representative parameter values. The simulations are calibrated so that the point denoted by a square is a symmetrical equilibrium with equal ratios of skilled to unskilled workers everywhere; the number of firms is then kept constant across equilibria. I have tried a wide range of parameter values and always found the same qualitative results. Sales of each variety and profit rates are always higher in large country firms, but increasing the proportion of the world belonging to the trade bloc improves the relative competitiveness of the small countries, and leads to an increase in the relative sales and profits of their firms."

Although the specific mechanisms operating in the model pass through consumer prices and migration, the main lesson the model teaches is very simple and can be read more broadly. An increase in the size of a trade bloc increases the size of the market that a firm in the bloc can reach with relative ease. This increase will be more significant for firms located in small countries, whose own domestic market is small. Thus if a firm enjoys competitive 
advantages from having access to larger markets, the entry of new members will favor particularly small country firms.

We can now finally address the main question of this paper: How is the welfare of the countries belonging to the trade bloc affected by the entry of new members? And more specifically, are the benefits of the enlargement falling mostly on small or large member countries?

Baldwin (1993) establishes that the gain from belonging to the trade bloc increases with the relative size of the bloc. This result is replicated here. Figure 3 reports the utility of skilled and unskilled workers in member countries relative to the utility of the same type of workers in nonmember countries, as function of the fraction of the world belonging to the bloc. In countries outside the bloc, the high transport costs translate into high consumer prices and, to allow firms a minimum of international competitiveness, into low nominal wages. Thus utility for all workers is lower then inside the trade bloc. The difference in both prices and wages increases with the size of the bloc, making the disparity stronger.

Within the bloc, in equilibrium unskilled workers anywhere have equal utility, and the possibility of a differential impact of enlargement on small and large country residents must concern skilled workers. Any national welfare function giving skilled workers any weight will move in the direction in which their utility moves. And any comparison between welfare in small and in large countries amounts to a comparison in skilled workers utility.

Using (12) and (14), we can rewrite (22) as:

$$
\frac{U_{L}{ }^{n}}{U_{S}{ }^{n}}=C \frac{Y_{L}(1+\sigma)-Y_{F}(\sigma-1)}{Y_{S}(1+\sigma)-Y_{F}(\sigma-1)} \frac{Y_{L}+Y_{F}}{Y_{S}+Y_{F}} \quad \forall L, S \text { belonging to the bloc; }
$$

where

$$
C \equiv\left(-\frac{H_{s} / k_{s}}{H_{L} / K_{L}}\right)^{2}
$$


Straightforward differentiation allows us to establish the following Proposition:

Proposition 4. If $Y_{L}>Y_{\mathrm{S}}$ and $\sigma \geq 2$, then a decline in $Y_{\mathrm{J}} / Y_{\mathrm{S}}$ implies a decline in $U_{\mathrm{L}}{ }^{n} / U_{\mathrm{s}}{ }^{n}$.

Proposition 4 states that unless the elasticity of demand is remarkably low - $\sigma \geq 2$ is equivalent to requiring a mark-up not larger than 100 per cent ${ }^{\circ}$ - a decline in relative sales of firms located in large versus small countries is sufficient to insure that the gains from the enlargement fall disproportionately on small countries. We know from the previous discussion that the change in relative sales reflects the change in relative costs and thus the different effect of the enlargement on economies of scale in the two types of countries. If lower barriers to trade have a disproportionate effect on countries with small domestic markets, then they will reap the largest share of benefits from the expansion of the trade agreement. Once again, the conclusion is very intuitive: reducing the importance of the size of the domestic market will play in favor of smaller countries.

This is indeed the conclusion that is consistently supported by the numerical simulations. Figure 4 reports the relative utility of skilled workers in large versus small countries for different sizes of the trade bloc relative to the world. We know from Figure 2 that relative sales of large countries firms fall as the trade bloc becomes larger. As expected, the relative utility of large country skilled workers also falls.

The important feature of the result is that it lends itself directly to empirical testing. If we accept the restriction on demand elasticities, the empirical analysis of relative sales volumes allows us to draw immediate inferences on countries' relative gains. Because the change in relative costs that accompanies the change in relative demands is equally reflected in all (non domestic) markets, we can study how relative sales of small and large countries to any one market have been affected by the enlargement of a trade bloc. The next section discusses 
some initial evidence in response to this question. ${ }^{\circ}$

\section{EMPIRICAL EVIDENCE}

In January 1986. Spain and Portugal joined the European Community. Between 1986 and 1992, imports from the Community more than doubled in real terms in both countries (Figure 5). Did the gains from the enlargement fall differently on small and large Community members?

To answer this question, we can study the behavior of relative exports to Spain and Portugal for small and large countries before and after 1986. Because we need a time series without other major changes in membership, we begin the sample in 1975: the U.K.. Denmark and Ireland joined the Community in 1973, and immediately following that date the adjustment is likely to have been incomplete. Greece joined in 1981 , but restricting the sample further would be too costly given the already scarce degrees of freedom. The Greek economy in 1981 was relatively small (Greek real GDP in 1981 was just above 5 per cent of German GDP), and it is hoped that easier access to the Greek market may have had only a negligible impact on the relative performance of the economies of the Community. Greece itself, however. cannot be part of our sample of countries. Thus we are left with four small countries - Belgium. Denmark. Ireland and the Netherlands - and four large ones - France, Germany, Italy and the U.K..

For each large country, we want to ask whether its exports to Spain and Portugal, relative to exports by each of the four small countries, have risen or fallen after 1986 by more than justified by its normal performance. Studying the behavior of ratios of exports has three main advantages. First, this specification follows directly the theoretical indications of the model: second, it induces stationarity in the data; and finally, and related to the previous point, it allows us to abstract from shocks to the Spanish and Portuguese economies that although 
very important need not have disrupted the relative behavior of other countries toward the two markets (most obviously, the advent of democracy).

Using yearly data from The Directions of Trade Statistics and IFS, I have regressed the ratio of large to smail country exports to Spain and Portugal (in U.S dollars) on a constant, the countries' real exchange rate, the ratio of the countries' real GDPs and a dummy variable equal to zero between 1975 and 1985, and one from 1986 to 1992 (all variables are in logarithms; the variables measuring relative exports and GDPs are logarithms of ratios). The countries' real exchange rate captures variations in competitiveness that are independent of the enlargement of the Community; the ratio of real GDPs controls for changes in relative size."

Estimating the parameters with OLS, I found that the regressions were overall well-behaved. Both in the case of exports to Spain and to Portugal, however. the residuals of 3 out of the 16 regressions failed to pass a Breusch - Godfrey LM test on the absence of autocorrelation at the 10 per cent significance level. The results from these regressions are reported below with an asterisk, to caution about the possible presence of misspecification. ${ }^{12}$

Table 1 reports the coefficients of the dummy variable and their standard errors in the two sets of regressions. The four small countries are at the head of the columns. and the four large countries at the head of the rows. Each box reports the coefficient of the dummy variable in the regression explaining relative exports from the country in the corresponding row and the country in the corresponding column (so for example - 0.44 is the estimated dummy coefficient in the regression of relative exports from France and Belgium to Spain, and 0.09 its standard error: over the period 1986-1992, on average French exports to Spain were as much as 35 to 50 per cent lower with respect to Belgian exports than justified by relative size and real exchange rates). In Table 2, I have reported the signs alone of the coefficients, or a zero when the estimated coefficient is not significantly different from zero.

If small countries were the principal beneficiaries of the enlargement, as the theory predicts, 
the dummy coefficients should be negative: positive if the main gainers were the large countries. The Tables show that in this very simple first investigation neither hypothesis is clearly supported by the data. In the regressions studying relative exports to Spain. 5 out of 16 dummy coefficients are significantly positive, and 5 are significantly negative; in the regressions studying exports to Portugal, 2 out of 16 dummy coefficients are significantly positive. and 6 are significantly negative. Looking at individual countries, the Tables indicate that France and the U.K. have lost market shares in Spain and Portugal with respect to the small countries (controlling for changes in size and real exchange rates), with a particularly large decline for the U.K. On the other hand. Germany and Italy have fared better: Italian exports in particular appear to have gained ground with respect to exports from all four small countries. with the possible exception of Belgian exports to Spain (although the point estimate is negative, the coefficient is not significantly different from zero).

What the Tables do not supply is a synthetic statistics allowing us to evaluate whether the data as a whole reject the hypothesis derived from the theoretical model. A priori. we want a system estimation technique that provides a joint test of the non-positivity of all the dummy coefficients. Although there are two few data points to support this procedure, it is possible to estimate as a system all equations referring to an individual country (for example the eight equations involving French exports to Spain and Portugal, relative to each of the four small countries). Comparing the likelinood function of the estimated system without constraints to the likelihood function obtained when the dummy parameters are forced to be non-positive. we have a summary test of the performance of each country.

When applied to each of the large countries, the test addresses the hypothesis that the country's exports to Spain and Portugal since 1986 have fallen or at best remained constant relative to all four small countries in the Community (controlling for changes in sizes and real exchange rates). A log-likelihood ratio test yields the following values: 4.91 for France, 19.99 
for Germany, 23.37 for Italy, 0 for the U.K.; the critical chi squared values with 8 degrees of freedom are 13.36 at 10 per cent probability, 15.51 at 5 per cent, and 20.09 at 1 per cent. Thus the hypothesis cannot be rejected for the U.K. and France, it is rejected for Italy at 1 per cent probability level, it is rejected for Germany at 5 per cent probability, but not at 1 per cent. ${ }^{13}$

The results of the formal test thus confirm what Tables 1 and 2 had led us to expect. The sample is very short, and the data points too few to reach any firm conclusion, but three observations can be added. First, the anomalous pattern of Italian exports may be related to the specific measures that have accompanied the entry of Spain and Portugal in the Community. In 1986, the principal obstacles to foreign imports still existing in the two countries were non-tariff barriers, affecting particularly goods in direct competition with domestic products. The main beneficiaries of the opening of the Spanish and Portuguese markets may thus have been those countries in the Community whose products more closely resemble Spanish and Portuguese products, Italy in particular. A more disaggregated analysis of exports by product is required to evaluate this interpretation.

Second, the sample is too short to allow any study of the impact of German unification on German exports, but assuming that such a dramatic structural change is completely captured by GDP and real exchange rates, as implicitly done here, is problematic. Again, a longer data series and possibly a more disaggregated analysis would provide more information.

Finally, the theory predicts that the differential impact of the enlargement on small and large countries should be related to the size of the enlargement itself. In 1986, Spain and Portugal's GDPs together were 8 per cent of the GDP of the Community they were joining; it seems plausible that more substantial changes in the size of a trade bloc would have effects that are easier to detect empirically. ${ }^{14}$

\section{CONCLUSIONS}


This paper asked whether small or large countries systematically benefit more from enlargement of a trade bloc in a world where scale effects are important. If a large domestic market translates into lower costs for firms, a reasonable prior suggested that large country firms would be likely to benefit most: their competitive advantage would work to insure them larger shares in the new markets. and higher profits. The paper has shown that this reasoning is mistaken for a simple, intuitive reason: it takes the source of the competitive advantage of large country firms as given. But if the difference in costs depends on the different size of the market that each firm can serve with relative ease, then easier access to foreign markets diminishes the importance of the size of the domestic country. Small country firms will see a decline in their relative cost disadvantage and will be the main beneficiaries of the enlargement of the trade bloc. The logic of the mechanism is so simple that I expect the result to be fairly general.

The analysis of Community data after the entry of Spain and Portugal in 1986 shows that the theoretical predictions are confirmed for France and the U.K., with both countries losing markets shares in Spain and Portugal, relative to the small Community countries. However. the theoretical hypothesis is rejected in the cases of Italy and to a lesser extent Germany. Several explanations for the mixed results are possible, including the differential impact of nontariff barriers before the entry of Spain and Portugal in the Community, and the possibility that the enlargement not be sizable enough to have generated empirically important differential effects for countries of different sizes. A longer sample and more disaggregated data are necessary to evaluate these interpretations.

The paper began by asking whether a decline in the relative power of large countries in the institutions of the European Union could be the counterpart of asymmetrical economic gains from enlargement. If purely economic gains fell mostly on large countries, then a reallocation 
of power could conceivably be the quid pro quo demanded by the smaller members. The answer is unambiguous: neither the theory nor the data indicate any asymmetric economic gain in favor of large countries as such. There is no simple economic mechanism to rationalize a redistribution of power in favor of small countries. Other considerations - the distribution of Structural Funds for example - are more likely to play a role in the debate over the distribution of power; these considerations are political more than economic and not tied systematically to the size of each country. 
Figure 1

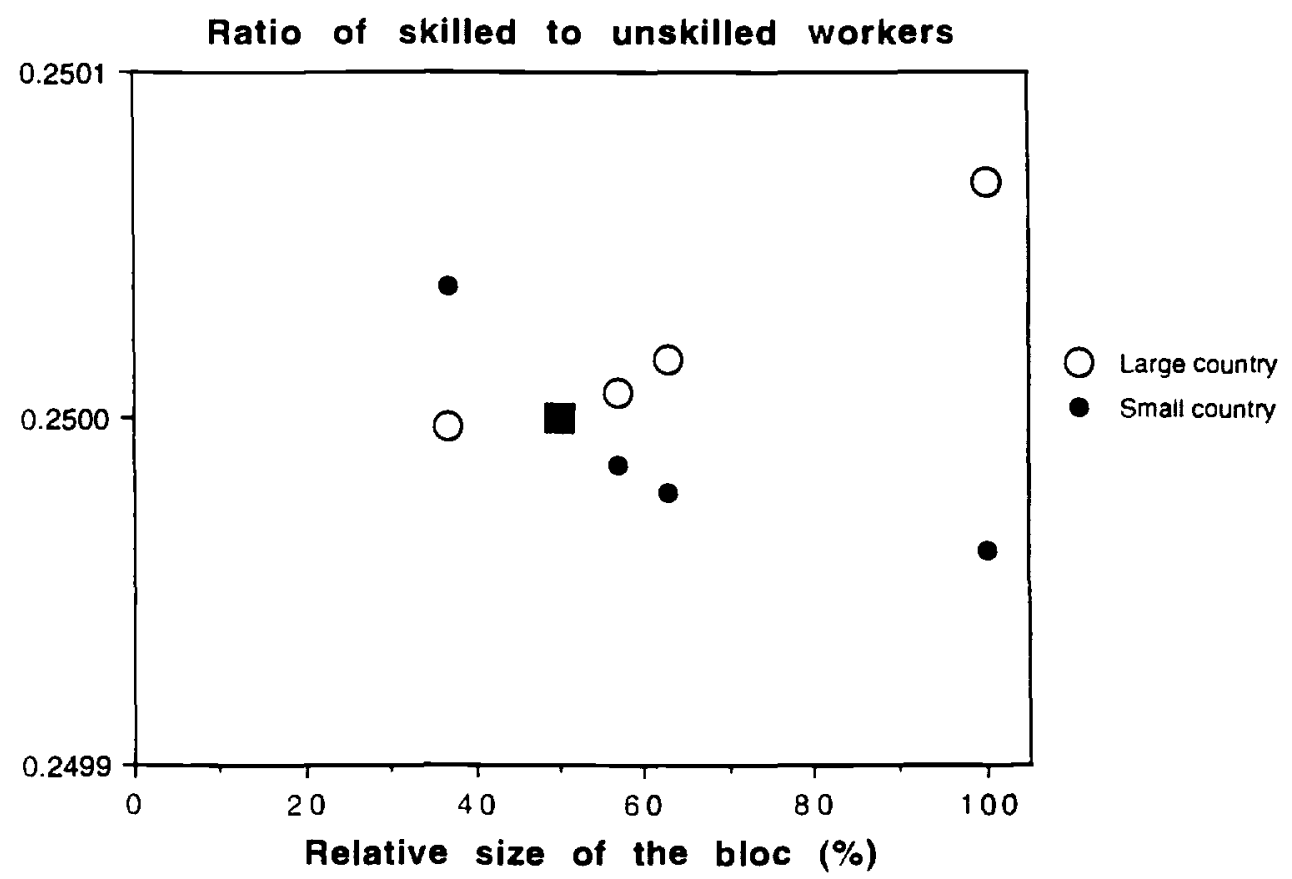

Price per variety

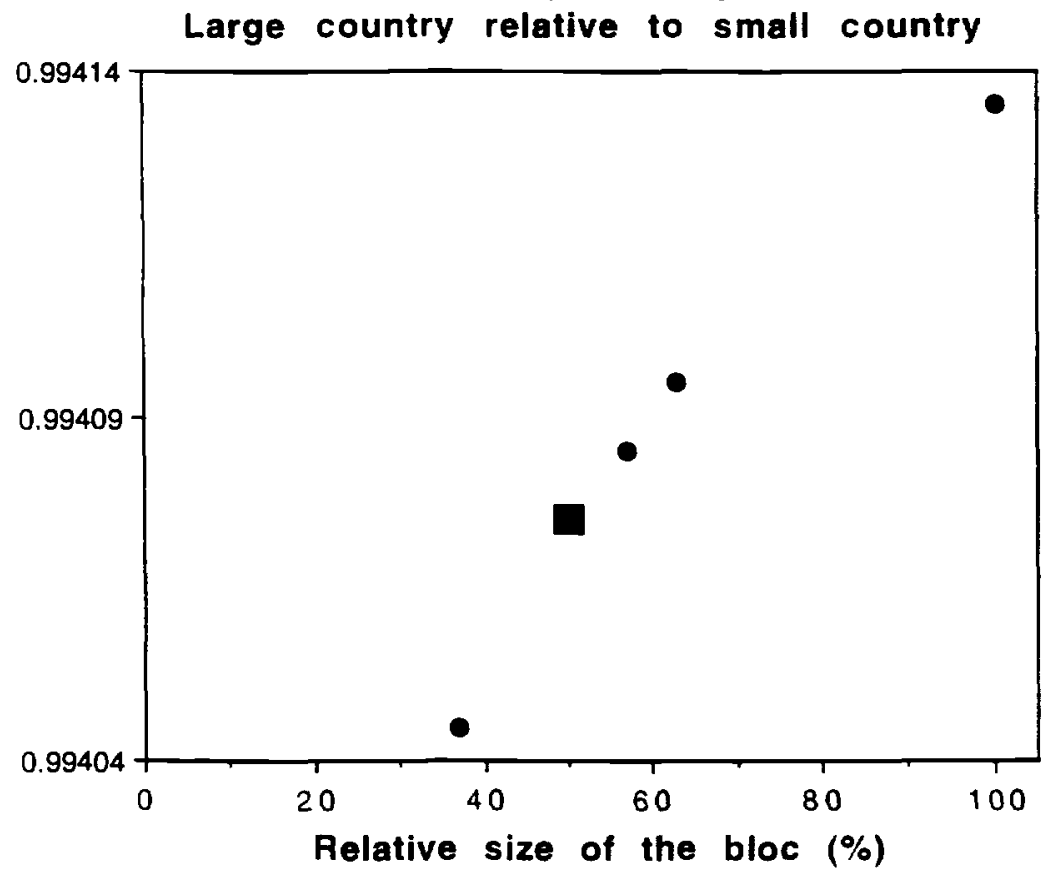


Figure 2

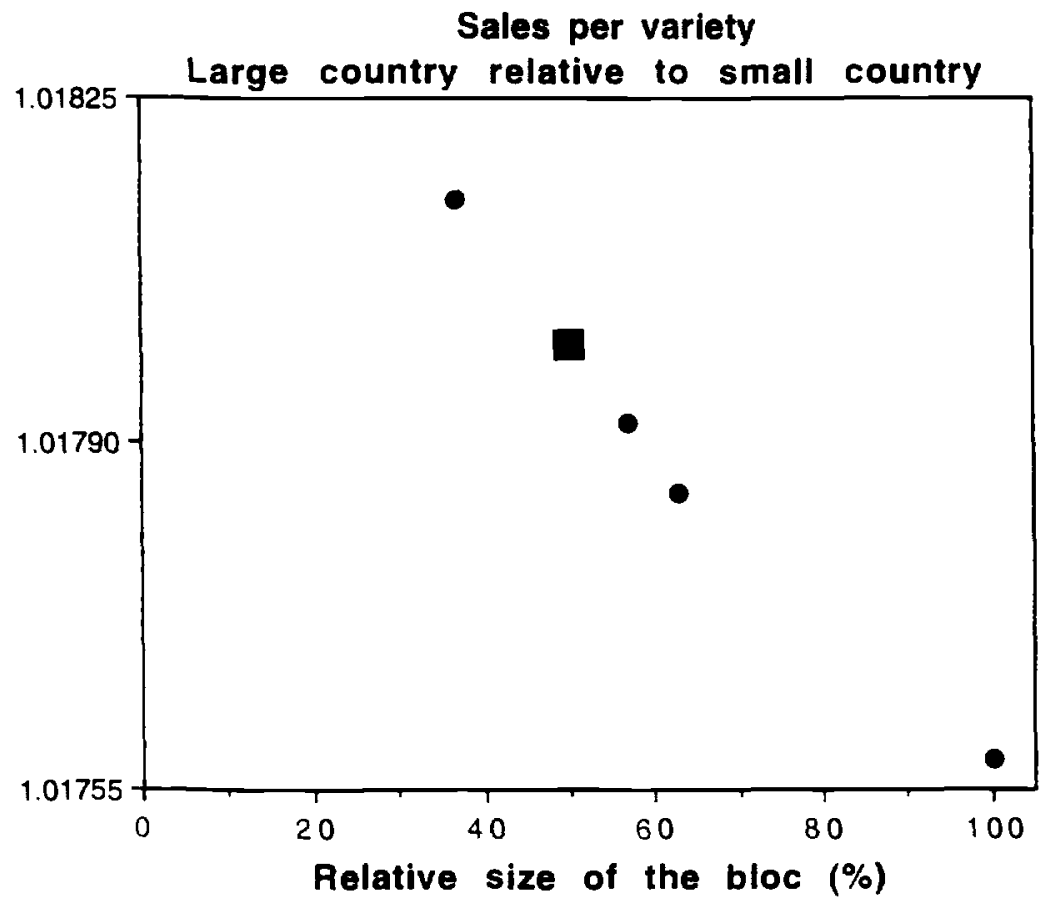

Profits per skilled worker

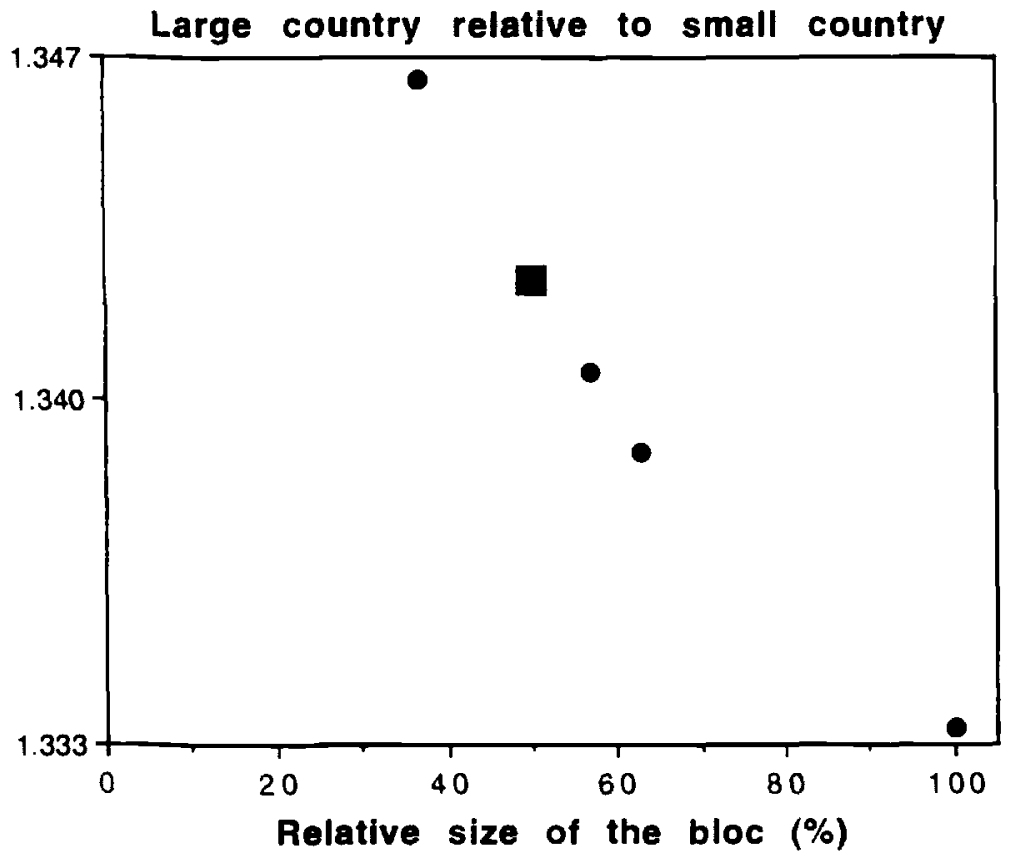


Figure 3

Utility of skilled workers

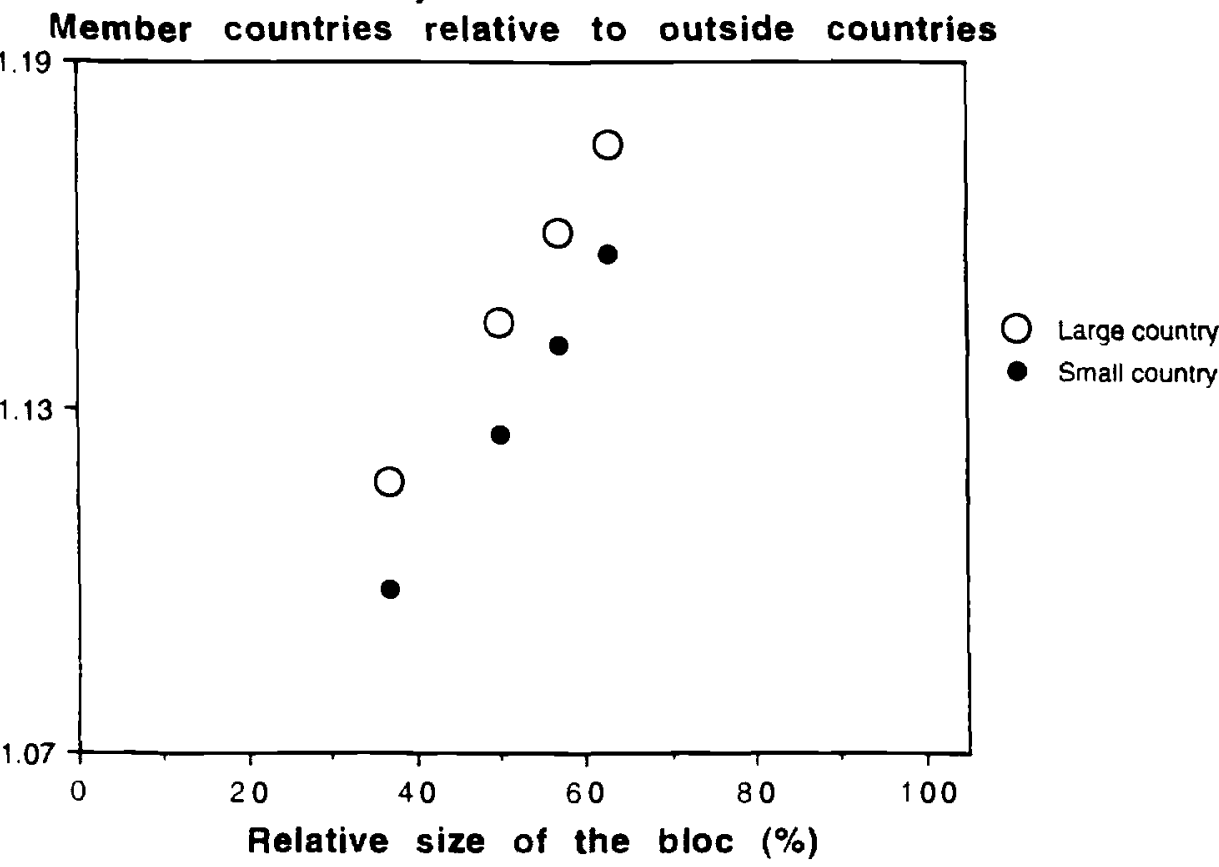

Utility of unskilled workers

Member countries relative to outside countries

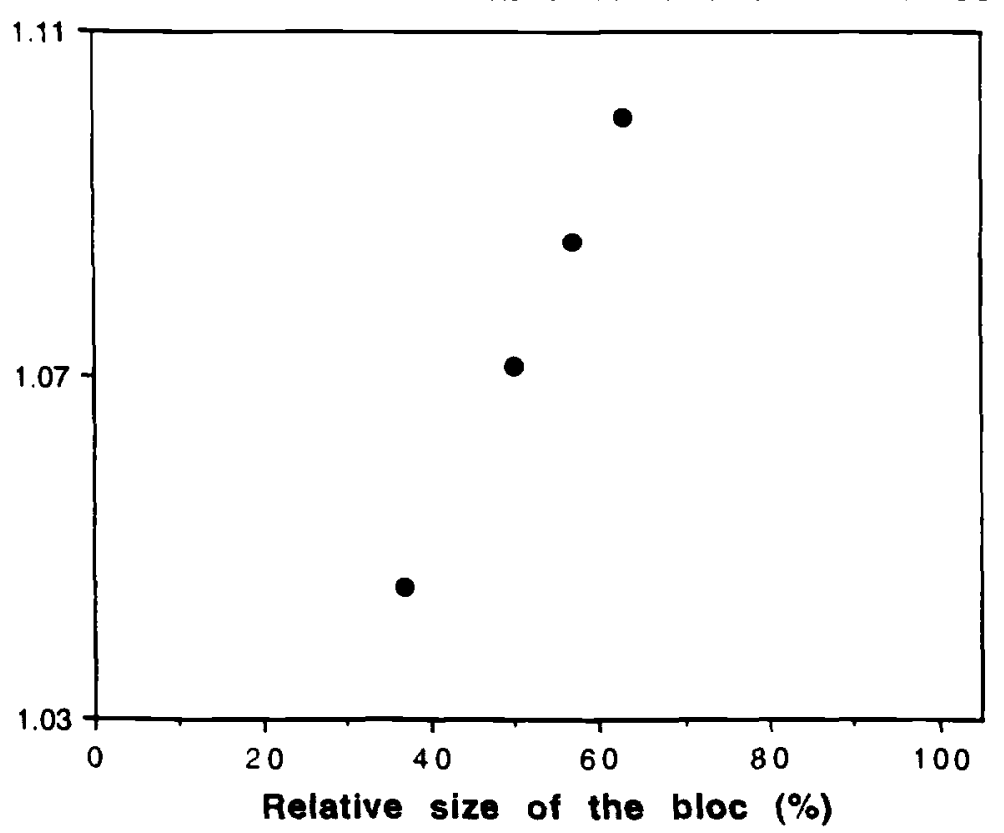


Figure 4

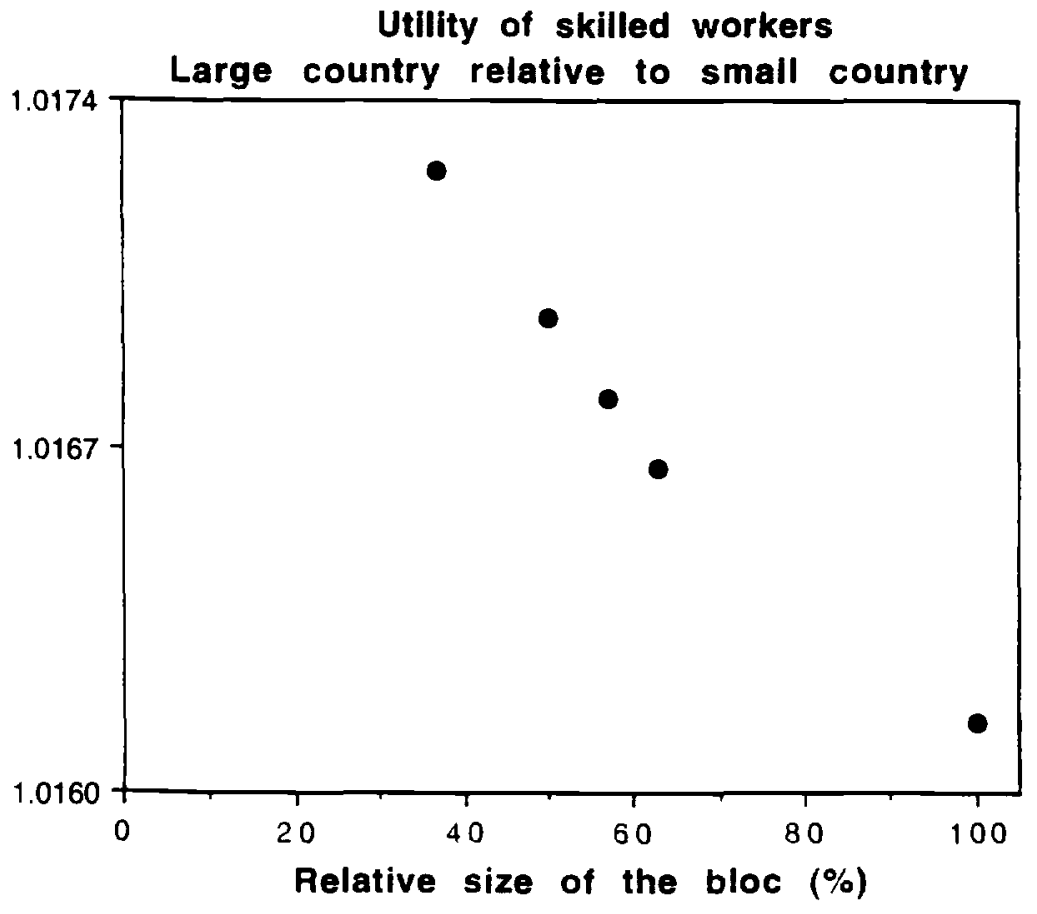


Figure 5
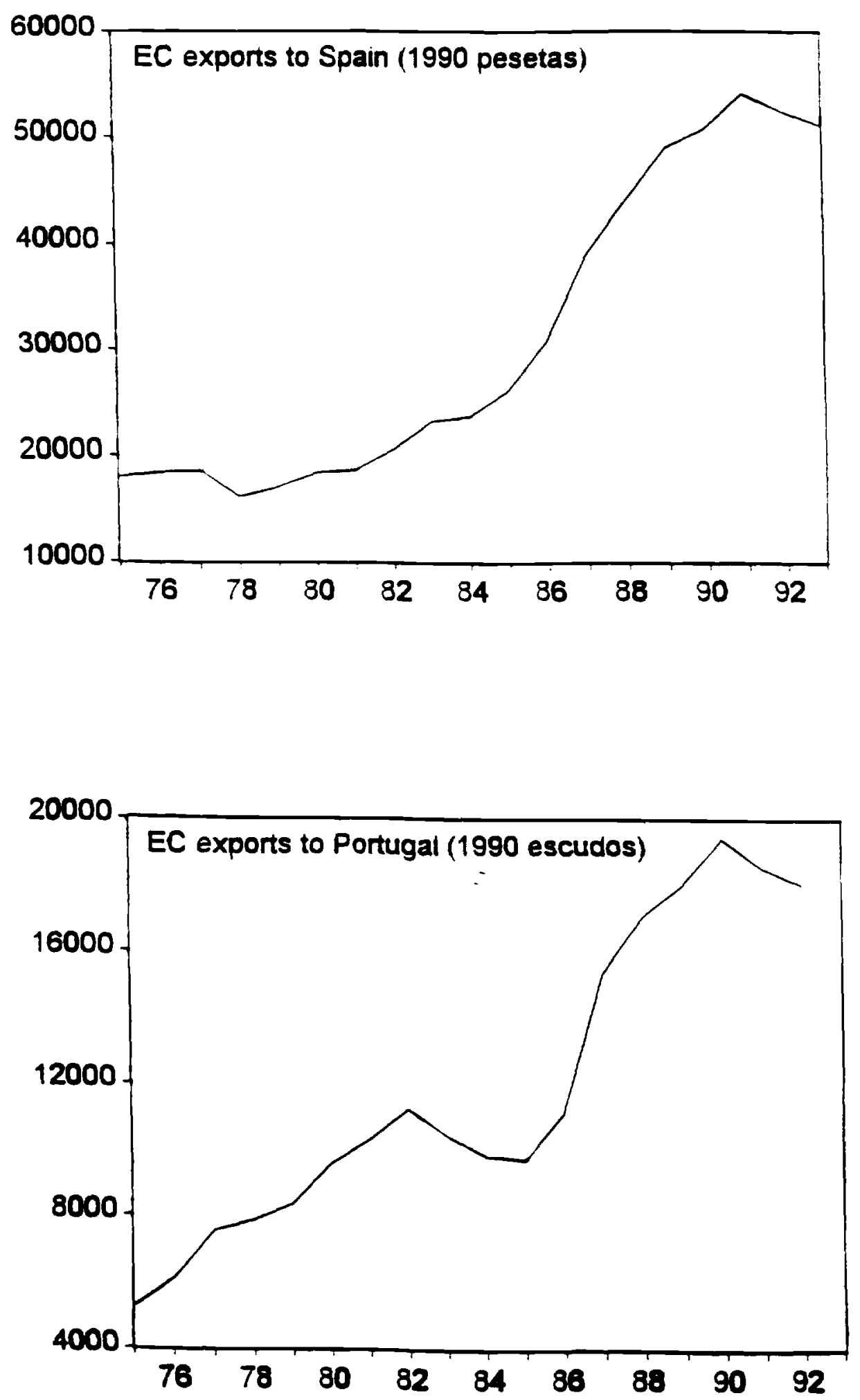

Countries: Belgium, Denmark, France, Germany, Ireland, Italy, Nethertands, United Kingdom Sources: Directions of Trade Statistics and IFS, IMF 
Table 1

Relative exports to Spain. Dummy coeficient

\begin{tabular}{|c|c|c|c|c|}
\hline & B & DEN & NL & IRE \\
\hline$F$ & $\begin{array}{l}-0.44 \\
(0.09)\end{array}$ & $\begin{array}{c}0.05 \\
(0.04)\end{array}$ & $\begin{array}{c}-0.07 \\
(0.03)\end{array}$ & $\begin{array}{c}0.18^{*} \\
(0.10)\end{array}$ \\
\hline $\mathbf{G}$ & $\begin{array}{l}-0.19 \\
(0.12)\end{array}$ & $\begin{array}{c}0.12 \\
(0.04)\end{array}$ & $\begin{array}{c}0.19 \\
(0.11)\end{array}$ & $\begin{array}{c}0.50 \\
(0.14)\end{array}$ \\
\hline 1 & $\begin{array}{c}-0.13 \\
(0.10)\end{array}$ & $\begin{array}{c}0.33 \\
(0.06)\end{array}$ & $\begin{array}{c}0.17 \\
(0.05)\end{array}$ & $\begin{array}{c}0.32 \\
(0.13)\end{array}$ \\
\hline UK & $\begin{array}{l}-0.67 \\
(0.09)\end{array}$ & $\begin{array}{c}-0.12 \\
(0.05)\end{array}$ & $\begin{array}{c}-0.15 \\
(0.04)\end{array}$ & $\begin{array}{l}-0.08 \\
(0.09)\end{array}$ \\
\hline
\end{tabular}

Relative exports to Portugal. Dummy coefficieny

\begin{tabular}{|ccccc||}
\hline & $B$ & $D E N$ & $N L$ & IRE \\
$F$ & -0.15 & -0.14 & $-0.04^{*}$ & 0.12 \\
& $(0.07)$ & $(0.09)$ & $(0.08)$ & $(0.26)$ \\
& & & & \\
& -0.26 & -0.34 & 0.21 & 0.06 \\
& $(0.08)$ & $(0.09)$ & $(0.10)$ & $(0.29)$ \\
& & & & \\
& 0.05 & 0.01 & 0.31 & 0.02 \\
& $(0.05)$ & $(0.09)$ & $(0.08)$ & $(0.25)$ \\
UK & -0.52 & -0.49 & -0.56 & -0.19 \\
& $(0.06)$ & $(0.12)$ & $(0.09)$ & $(0.21)$ \\
\hline
\end{tabular}


Table 2

Relative exports to Spain. Dummy coefficient

\begin{tabular}{|ccccc|}
\hline & B & DEN & NL & IRE \\
F & - & 0 & - & $0^{*}$ \\
G & 0 & + & 0 & + \\
I & 0 & + & + & $+*$ \\
UK & - & - & - & $0^{*}$ \\
\hline
\end{tabular}

Relative exports to Portugal. Dummy coefficient

\begin{tabular}{|ccccc|}
\hline & B & DEN & NL & IRE \\
F & - & 0 & $0^{*}$ & 0 \\
$G$ & - & - & + & 0 \\
UK & 0 & 0 & + & 0 \\
\hline
\end{tabular}




\section{FOOTNOTES}

* This paper was prepared for the Summer 1995 meeting of the International Seminar in Open Macroeconomics, Frankfurt, June 18-20. I thank the two organizers, Ken Rogoff and Charles Wyplosz, for inviting me to the seminar, and Torsten Persson, Giorgio Basevi, the participants to the meeting, the editor of this journal and an anonymous referee for their comments. The paper has also benefited greatly from being presented at the 1995 NBER Summer Institute in International Trade. In particular, I thank Richard Baldwin, Jim Levinsohn and Robert Staiger for suggestions that have clarified the exposition and strengthened the results. Finally, I thank Dani Rodrik for his comments and advice.

1. The importance of the size of the domestic market in determining countries' international performance is a recurring theme in international trade theory. See, for example, Basevi (1970) and the references cited there (in particular Drèze (1960)).

2. The assumption that unskilled labor is more mobile than skilled labor seems appropriate for the European case, and is commonly made in the literature; see for example, Wildasin and Wellisch (1995). Notice that if outside countries are all of equal side, an equilibrium in which they all have equal ratios of skilled to unskilled workers can be supported with free mobility of unskilled labor among them.

3. Complete domestic ownership of the profits is not required for the results, but it is required that profits from domestic firms benefit domestic residents disproportionately.

4. In Krugman and Baldwin's models, wages are equalized across countries through the existence of a competitive sector with constant returns that by assumption does not incur transport costs. Therefore large countries' firms do not benefit from any cost advantage (although they may realize higher profits because they face higher demand). In this set-up, a generalized increase in demand caused by the entry of new members into the trade bloc will affect equally large and small countries because their relative costs and production prices will not change (equations 4). The approach does not capture the link we want to study between market size and competitiveness.

5. An alternative solution strategy is to assume free entry and zero profits in all countries. However, with the functional forms assumed in the model, this amounts to assuming a competitive edge for firms located in small countries (because the level of output must be equal everywhere and there are costs to foreign trade). This runs counter to the starting point of the policy debate, and does not seem to me a desirable assumption. In any event, the main mechanisms through which enlargement affects the different countries in the bloc remain identical whether or not firms can freely enter the market, and both the welfare implications and the empirical predictions on the level of exports are unchanged. The Appendix discusses the zero-profit case.

6. More precisely, outside countries face lower demand than bloc countries of equal size. To generate full employment and non-negative profits, they must have lower wages, while at the same time having higher consumer prices. In comparison with small inside countries, large outside countries could have lower consumer prices and higher utility for skilled workers. Notice that, as is well-known, this model cannot explain on the basis of economic reasons 
alone why countries of any size may prefer to remain outside the bloc (see the discussion in Baldwin (1993)).

7. Call $P_{L}^{\circ}$ and $P_{S}{ }^{\circ}$ the price deflators in large and small countries in the bloc before enlargement, and $P_{L}^{\prime}$ and $P_{S}^{\prime}$ the same deflator after one extra country has joined the bloc. at given wages and profits. By equations (17):

$$
\left(\frac{P_{L}{ }^{\prime}}{P_{S}{ }^{1}}\right)^{o}=\left(\frac{P_{L}^{\circ o}-k_{o} \tau^{1 \sigma}+k_{\mu} \mu^{10}}{P_{s}^{\circ o}-k_{o} \tau^{1 \sigma}+k_{\alpha} \mu^{10}}\right)
$$

With $\tau>\mu$, and $\sigma>1,(\mathrm{~F} 1)$ implies $\mathrm{P}_{\mathrm{L}}^{1} / \mathrm{P}_{\mathrm{S}}{ }^{1}>\mathrm{P}_{\mathrm{L}}^{0} / \mathrm{P}_{\mathrm{S}}{ }^{0}$ if $\mathrm{P}_{\mathrm{L}}^{0} / \mathrm{P}_{\mathrm{S}}{ }^{0}<1$.

8. In all simulations reported here, $Y_{F}=1, \mu=1.1, \tau=1.25, \sigma=2$. I have set $H_{L}=50, H_{S}=$ $H_{0}=10, N_{s}=5, N_{s}+N_{0}=45, \theta_{0}=1 / 4$ and $L=2,800$ (thus the total population equals 3,500 ). The proportion of the world belonging to the trade bloc goes from a lower bound of 0.37 , when a single small country is in the bloc, to an upper bound of 1 when $N_{0}=0$ (in which case $w_{1}$ is the numeraire). I have assumed that outside countries are small because the most common question concerns the entry of several small countries into the bloc, but the results do not change significantly in the alternative case. Allowing outside countries to have different sizes would greatly complicate both the model and the simulations, with no obvious payoff. The number of firms in each country is chosen so as to yield $\theta_{\mathrm{L}}=\theta_{\mathrm{s}}=\theta_{\mathrm{o}}$ and $\pi_{\mathrm{o}}=0$ when half of the world belongs to the trade bloc $\left(N_{s}=10\right)$. (Integer constraints are ignored, and the procedure results in $k_{\mathrm{L}}=48.28, \mathrm{k}_{\mathrm{S}}=9.75, \mathrm{k}_{\mathrm{o}}=10$ ). Notice that there is a small problem: when a country enters the bloc, keeping the model tractable requires making the new member identical to a country of equal size already in the bloc (otherwise we would be adding a fourth type of countries), and thus changing the number of firms. We can think of this as an approximation to a long run equilibrium where in each country the number of firms is determined by the endowment of a fixed factor required for production and collecting all rents (as in Flam and Helpman, 1987). I see no reason to believe that the results are dependent on this simplification.

9. The condition $\sigma \geq 2$ is sufficient for the result, but is much more stringent than required.

10. In domestic markets, changes in relative sales reflect both changes in domestic population and changes in relative costs. Notice that if the elasticity of demand is constant, as in this model, the size of the foreign market we choose is irrelevant.

11. If the only source of changes in relative competitiveness were the enlargement, as in the stylized theoretical model, the real exchange rate variable and the dummy would be collinear, and the parameters difficult to estimate. More generally, the real exchange rate variable will capture factors affecting relative competitiveness that are independent of the size of the Community. The same argument holds for relative real GDPs. Notice that the simple regression equation derived from the model is consistent with other empirical approaches. For example, Frankel, Stein and Wei (1995) discuss bilateral trade flows on the basis of a gravity model of trade. In the cross section equation they estimate, trade flows are explained by the variables discussed here, plus a series of geographical characteristics (for instance. physical distance between two countries and the sharing of a common border). In the absence of major political changes these characteristics remain constant over time; here they are simply be captured by the constant. 
12. The regressions are available from the author. A few details: (1) The real exchange rates series were constructed for each pair of countries using as price indexes either the GDP deflator or labor costs. The results were not sensitive to the choice. The coefficients reported in the Tables are drawn from the regression that appeared slightly superior, yielding higher level of significance for all parameters, lower autocorrelation of residuals and higher $\mathrm{R}^{2}$. (2) With the data on exports in U.S. dollars, the sign of the coefficient of the relative real exchange variable depends on elasticities, and indeed was not found to be consistent across all pairs of countries. (3) On the contrary, the coefficient of the relative size variable was positive, as expected, or in a few cases insignificantly different from zero. (4) The $R^{2}$ varied mostly between 0.5 and 0.9 , with a few lower values. The regression of French to Dutch exports to Portugal had the lowest $R^{2}$ at 0.16 , and was clearly unsatisfactory (all parameters were not significantly different from zero, and the residuals showed evidence of autocorrelation). In all other regressions with low $A^{2}$ there was no other obvious symptom of misspecification.

Several regressions invoiving Germany had consistently low $A^{2}$ of around 0.5 , and excluding data after 1990, to check whether the lack of explanatory power was due to a structural break corresponding to German unification, did not improve the fit (the sample is too short to test for stability of the coefficients).

13. As expected, the estimates obtained through system estimation are more efficient. The point estimates of the dummy parameters are almost unchanged; the only important difference is that the dummy parameters in the regressions of Italian/Belgian exports to Spain and French/Danish and British/Irish exports to Portugal are now significantly negative. As mentioned above, the OLS estimation uncovered signs of possible specification problems in a few equations; the system estimation may spread those problems to all equations, and the results should be seen with some care.

14. Recall that the mechanism leading to a bias favoring small countries is the asymmetry in the decline of the share of the domestic market, following the entry of new members. Comparing the impact of the 1986 enlargement on France and the Netherlands, for example. the French share of Community GDP fell by 2.6 percentage points, (from 22.7 to 20.1 per cent), the Dutch share by slightly less than half a percentage point (from 5.5 to 5.1 per cent). It is easy to show that the decline in the country share is always larger for large countries, and the difference increases with the size of the enlargement. Notice that as proportion of the initial country share the decline is always necessarily identical for all countries, but it is the absolute decline that matters for our purposes. I thank Torsten Persson for suggesting these numbers. 


\section{REFERENCES}

Baldwin. Richard. 1993, "A Domino Theory of Regionalism", NBER Working Paper No. 4465 September.

Basevi, Giorgio, 1970, "Domestic Demand and Ability to Export". Journal of Political Economy, 78, March/April

Drèze, Jacques, 1960, "Quelques réflexions sereines sur l' adaptation de l' industrie belge au Marché Commun" Comptes rendus des travaux de la Société Royale d' Economie Politique de Belgique, no. 275, December.

Flam, Harry and Elhanan Helpman, 1987, "Industrial Policy under Monopolistic Competition", Journal of International Economics, 22, 79-102.

Frankel, Jeffrey, Ernesto Stein and Shang-Jin Wei, 1995, "Continental Trading Blocs: Are They Natural, or Super-Natural?", Journal of Development Economics, forthcoming.

Krugman, Paul, 1991a, "Increasing Returns and Economic Geography", Journal of Political Economy, June.

Krugman, Paul, 1991b, Geography and Trade, MIT Press: Cambridge, Ma.

Widgrén, Mika, 1994a, "Voting Power in the EC Decision Making and the Consequences of Two Different Enlargements", European Economic Review, 38, 1153-70.

Widgrén, Mika, 1994b, "The Relation Between Voting Power and Policy Impact in the European Union", CEPR Discussion Paper No. 1033, October.

Wildasin, David and Wellisch, 1995, "Tax Competition and Migration", European Economic Review, forthcoming. 


\section{APPENDIX}

Proposition 1. Consider an equilibrium where $\theta_{\mathrm{L}}=\theta_{\mathrm{s}}=\theta_{\circ}$. Then, for any $w_{\mathrm{s}}{ }^{*}<w_{1}$, there exists a $\mu^{*}>1$ such that for all $\mu<\mu^{*}, w_{\mathrm{s}}^{*}$ cannot occur in equilibrium.

For all $w_{s}<w_{L}$, if $\theta_{L}=\theta_{s}$ equation (16) requires $P_{L}>P_{s}$, or, using $(17),\left(k_{\mathrm{L}} / k_{s}\right)<$

by (12) and (21), there exists $\mu^{*}>1$ such that for all $\mu<\mu \mu^{*}, \pi_{\mathrm{S}}>\pi_{\mathrm{L}}$ if $w_{\mathrm{S}}<w_{\mathrm{L}}$. Therefore,

using equation (14), for all $\mu<\mu^{\prime \prime},\left(k_{\lrcorner} / k_{s}\right)>H_{\lrcorner} / H_{s}$, and $w_{s}<w_{L}$ can occur in equilibrium only if $\left(W_{J} / w_{s}\right)^{o .1}>H_{\lrcorner} / H_{s}$. Following equation (16), $\left(w_{v} / w_{s}\right)^{\sigma .1}=\left(P_{J} / P_{s}\right)^{\sigma} ;$ thus it must be the case

$P_{J} / P_{s}>\left(H_{J} / H_{s}\right)^{1 / a}$. By $(17)$ this condition is violated for all $\mu \leq\left(H_{J} / H_{s}\right)^{1 /(0-1)}$ (larger than 1).

Therefore there exists $a \mu^{*}>1$ and equal to the $\min \left(\mu^{* *},\left(H_{\mathrm{L}} / \mathrm{H}_{\mathrm{s}}\right)^{1 /(0-1)}\right)$ such that for all $\mu<\mu^{*}, w_{\mathrm{s}}$ $<W_{L}$ cannot occur in equilibrium.

Proposition 2. Consider an equilibrium where $\theta_{\mathrm{L}}=\theta_{\mathrm{S}}=\theta_{\circ}$. Then, for any $w_{\mathrm{S}}{ }^{*}>w_{\mathrm{L}}$ there exists a $\mu^{*}>1$ such that for all $\mu<\mu^{*}, \pi_{\mathrm{L}}>\pi_{\mathrm{s}}$.

The proposition follows directly from (12) and (21).

\section{The Zero Profit Case}

As mentioned in footnote 5 , the model can be solved assuming zero profits and using equation (14) to determine the endogenous number of firms in each country. In this case, the scale of activity is identical for all firms anywhere located, wages and producer prices adjust to generate the appropriate demand, and the mobile labor force migrates out of small countries to equalize utility. In all equilibria, the ratio of skilled to unskilled labor is lower in large countries than in small countries, and producer prices are higher.

When new countries become members of the trade bloc, consumer prices fall by more in small countries, inducing relatively larger immigration of unskilled workers and a decline in producer prices. The larger population is employed by a larger number of firms, and the ratio of firms in large versus small countries falls. At the same time, relative skilled wages in large versus small countries fall. In conclusion, total production and exports rise by more in small countries, and so does the utility of the skilled workers and the welfare of the countries. With respect to the non-zero profit case discussed in the text, the initial equilibrium differ, but the mechanisms through which the system adjusts to an enlargement of the bloc are unchanged, and thus the conclusions are unchanged. Figure A1 presents the relative number of firms and the relative utility of skilled workers in large versus small countries as function of the relative size of the bloc, at the parameter values used in the numerical simulations discussed in the text. 
Figure A1
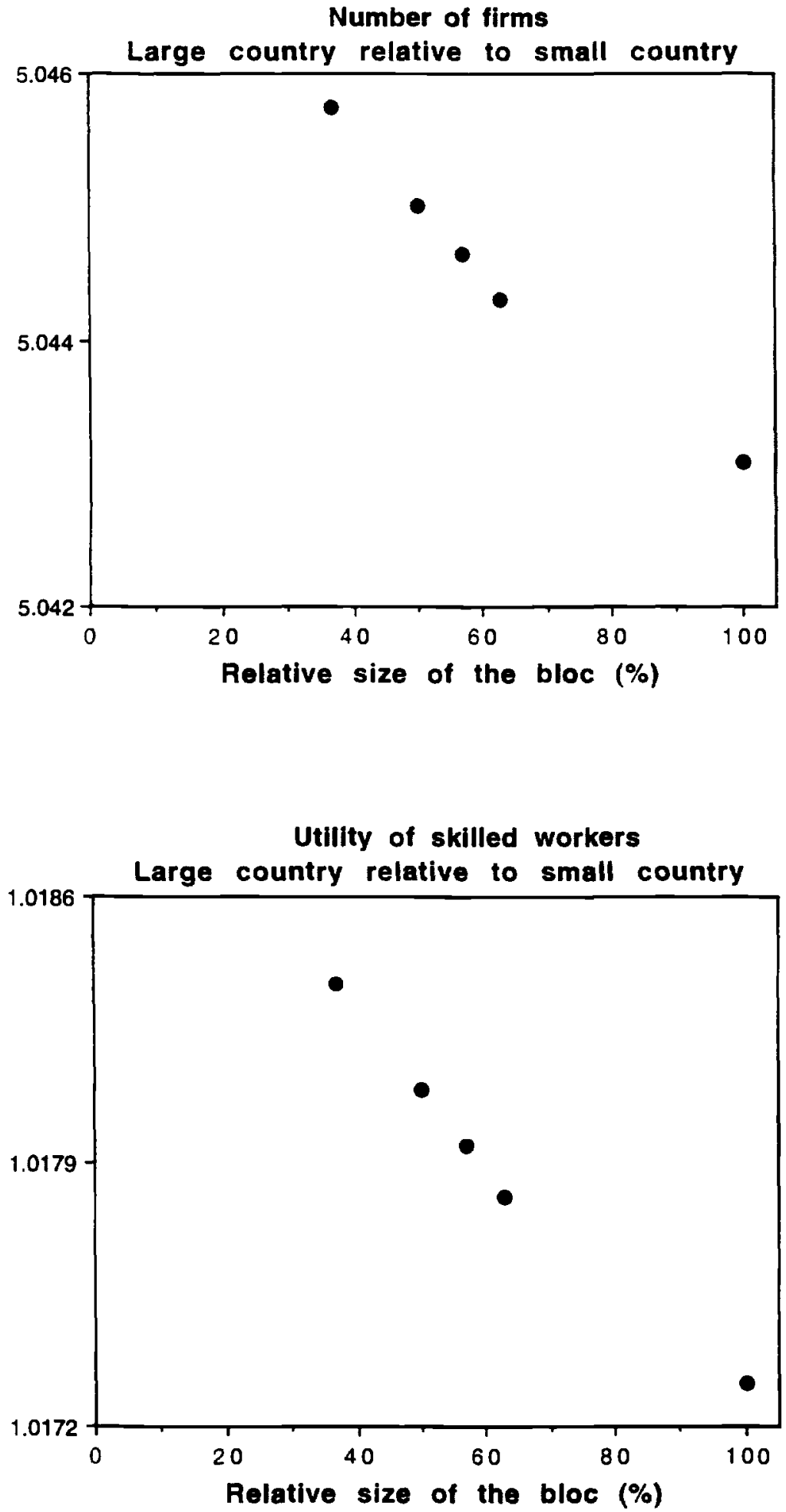